Clinical governance in the context of primary care groups has the potential to improve the quality of health care for patients and the working lives of health professionals. The model we have proposed offers a practical framework for interlinking the various activities. It emphasises improving performance, and shows how groups can gradually develop their own system of governance. It offers a feasible approach to the introduction and monitoring of clinical governance in primary care groups, and its wide adoption would be likely to help promote both quality improvement and accountability.

Contributors: RB and ML undertook the initial development of the model, which was developed further by RF and FC. The paper was written jointly by RB, ML, RF, and FC. RB is the guarantor.

Funding: The Eli Lilly National Clinical Audit Centre is jointly core funded by Eli Lilly and Company Ltd and Leicestershire Health Authority.

Competing interests: None declared.

1 Secretary of State for Health. A First Class Service. London: Department of Health, 1998.

2 Scally G, Donaldson LJ. Clinical governance and the drive for quality improvement in the new NHS in England. BMJ 1998;317:61-5.

3 Robertson N, Baker R, Hearnshaw H. Changing the clinical behaviour of doctors: a psychological framework. Quality in Health Care 1996;5:51-4.

4 Grol R. Beliefs and evidence in changing practice. BMJ 1997;315:418-21.

5 Bero LA, Grilli R, Grimshaw JM, Harvey E, Oxman AD, Thomson MA on behalf of the Cochrane Effective Practice and Organisation of Care Review Group. BMJ 1998;317:465-8.

6 NHS Executive. The new NHS, modern, dependable-developing primary care groups. Leeds: Department of Health, 1998. (HSC 1998/139.)
7 General Medical Council. Good medical practice. London: General Medical Council, 1998.

8 United Kingdom Central Council for Nursing, Midwifery, and Health Visiting. Code of conduct for the nurse, midwife and health visitor. 3rd ed. London: UKCC, 1992.

9 Department of Health. National Health Service (general medical services, regulations 1992. Schedule 2. Terms of service for doctors. London: HMSO, 1992. (SI 1992/635.)

10 Conference of Postgraduate Advisers in General Practice. Summative assessment: general practice training. Winchester: National Office for Summative Assessment, 1996.

11 Berwick D. Heal thyself or heal thy system: can doctors help to improve medical care? Quality in Health Care 1992;1(suppl):2-8.

12 Smith R. All changed, utterly changed. BMJ 1998;316:1917-8.

13 Zazove P, Klinkman MS. Developing a CQI program in a family medicine department. J Quality Improvement 1998;24:391-406.

14 Hearnshaw H, Baker R, Cooper A. A survey of audit activity in general practice. BrJ Gen Pract 1998;48:979-81.

15 Fraser RC, Lakhani MK, Baker RH, eds. Evidence-based audit in general practice. From principles to practice. Oxford: Butterworth-Heinemann, 1998.

16 Clinical Standards Advisory Group. Clinical effectiveness. London: Stationery Office, 1998.

17 Grol R, Dalhuisen J, Thomas S, Veld C, Rutten G, Mokkink H. Attributes of guidelines that influence use of guidelines in general practice: observational study. BMJ 1998;317:858-61.

18 Baker R, Fraser RC. Is ownership more important than the scientific credibility of audit protocols? A survey of medical audit advisory groups. Fam Pract 1997;14:107-11.

19 Baker R. General practice in Gloucestershire, Avon and Somerset: explaining variations in standards. Br J Gen Pract 1992;42: 415-8.

20 Chief Medical Officer. A review of continuing professional development in general practice. A report by the chief medical officer. London: Department of Health, 1998.

21 Fraser RC, McKinley R, Mulholland H. Consultation competence in general practice: establishing the face validity of prioritised criteria in the Leicester assessment package. Br J Gen Pract 1994;44:109-13.

22 Williams S, Michie S, Pattani S. Improving the health of the NHS workforce. London: Nuffield Trust, 1998.

23 Secretary of State for Health. The new NHS, modern, dependable. London: Stationery Office, 1997. (Cm 3807.)

(Accepted 21 January 1999)

\title{
Towards primary care groups Managing the future in Bradford
}

\author{
S R Proctor, J L Campbell
}

This paper describes the processes and experiences of key players in Bradford, West Yorkshire, of setting up primary care groups (PCGs)-from initial reactions to the government's white paper, ${ }^{1}$ through configuration and establishing the boards, to planning and delivering the main tasks before going live on 1 April 1999.

Bradford is one of the 10 largest cities in England. Bradford Health Authority serves the population of the city and surrounding areas. It is an area of great diversity, which incorporates some moderately affluent suburban communities as well as areas of substantial deprivation, poor housing, and high unemployment (box). The area is lively and culturally rich and includes some of the most beautiful countryside in England.

The diversity of the area is also reflected in its primary care provision. This includes two total purchasing pilots (groups of general practitioners who purchase hospital and community health services outside fundholding). ${ }^{1}$ A range of fundholding practices have collaborated to develop joint contracts for commissioning a range of services. The district also has a substantial number of singlehanded practices, particularly in the inner city, and many of these have collaborated to form a support organisation for small practices. Despite the diverse needs of the communities served by primary care services in Bradford, sharing

\section{Summary points}

The introduction of primary care groups from April 1999 heralds some of the most sweeping changes ever in the NHS

The boards of these groups comprise general practitioners and nurses, and social services, health authority, and lay representatives

They have a collective responsibility for commissioning secondary care, delivering primary care, ensuring quality, measuring performance, reducing health inequalities, and improving the health of the population served

The timescale from configuration to "going live" is only eight months

New relationships have to be established, new ways of working developed, new objectives clarified, and action plans set
This is the first of four articles showing how primary care groups have been set up in various areas in Britain

Department of General Practice and Primary Care, Guy's, King's, and St Thomas's School of Medicine, London SE11 6SP

S R Proctor,

lecturer in health

services research

J L Campbell, senior lecturer

Correspondence to: Dr Proctor s.proctor@ umds.ac.uk

Series editor: Trish Groves

BMJ 1999;318:783-5 
ideas between practices and working collaboratively is, in certain parts of the district, established. The district has recently become a health action zone and aims to build on existing partnerships across agencies and to work to reduce health inequalities.

\section{Responses to the white paper}

Initial reaction among many general practitioners to the notion of primary care groups was mixed. Dr John Givans, secretary of the local medical committee, felt that generally people were looking for a period of consolidation and quiet, and recalled the difficulties in generating enthusiasm among many general practitioners. "I think in theory the idea of working in partnership with other agencies like social services is viewed as a good thing," he said, "but in practice there is some trepidation on the part of general practitioners, as we are talking about very different cultures. As far as sharing decisions with nurses, in my opinion that is long overdue." He felt that the potential for primary care groups is great: "for patients it could lead to better equity; better and more consistent standards of quality. There is an opportunity for a significant number of general practitioners who want to be salaried employees to be so, and an opportunity for the independent contractor status to continue." But there is also a threat to general practice if primary care groups become like health maintenance organisations: "this could force all general practitioners to be salaried and lead to a cheap and nasty service. General practitioners need to maintain their influence."

There were some misgivings about the proposed size of the groups, at approximately 100000 patients. Dr Tim Callaghan, a fundholding general practitioner (now a board member of South and West Bradford Primary Care Group), suggested that a smaller number of 50000 to 60000 patients was ideal in balancing representation of general practitioners and flexibility in changing contracts with providers.

Other changes are viewed positively-for example, developing partnership with other agencies. Dr Maggie Helliwell (former chair of the Worth Valley Consortium, now chair of the Airedale Primary Care Group) believes that primary care groups are a natural progression from total purchasing, and that partnership with social services makes sense. Philip Lewer, assistant director of social services and now board member of the City

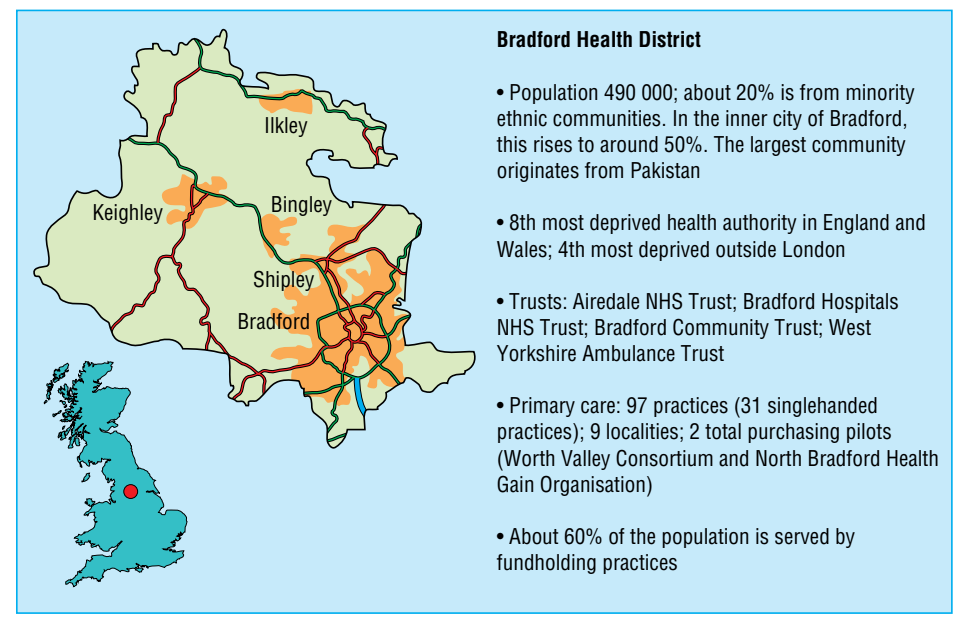

Primary Care Group, spoke of the history of shared working between the health authority and social services, which could potentially be further developed and extended by the primary care groups. He perceived that some general practitioners are "bemused" by the involvement of social services in primary care groups, but he felt optimistic about their future together.

In the North Bradford total purchasing pilot, even before the white paper had appeared, Dr Peter Rennie (now chair of North Bradford Primary Care Group) and colleagues had tried to anticipate what might be the next development for the total fund. They had started consultation with general practitioners in practices within the locality, talking about how total purchasing might be extended, and where future primary care developments might lead. He has some reservations, though: "I think there is a tension between flexibility and accountability in the PCGs. In fundholding in many ways you flew by the seat of your pants-trying out new ideas and if they didn't work you just dumped them and moved on to the next thing. In PCGs you can't do this-you need proper business plans, need to think about funding and developing a strategy-not working by trial and error. I suspect it will be even more so in primary care trusts-there is a risk of discouraging innovation."

\section{Configuration of primary care groups}

The process of configuration was led by the health authority in accordance with central guidance. Ann Wagner, director of performance management, described the lengthy process of consultation, negotiation, and compromise. Firstly, general practitioners were asked to consult key stakeholders in their area in preparation of initial proposals for primary care groups. A wider consultation led by the Health Authority was then conducted across the district. This resulted in four primary care groups:

- City (population $146600,17.4 \%$ patients under 10 years, $9.4 \%$ patients aged 65 and over, $54.1 \%$ from ethnic minorities);

- Airedale (population $116450,12.7 \%$ patients under 10 years, $16.7 \%$ patients aged 65 and over, $8.1 \%$ from ethnic minorities);

- South and West (population 147 100, 12.6\% patients under 10 years, $14.3 \%$ patients aged 65 and over, $4.5 \%$ from ethnic minorities); and

- North (population $91850,12.1 \%$ patients under 10 years, $16.6 \%$ patients aged 65 and over, $3.0 \%$ from ethnic minorities).

Each of the four boards has seven general practitioners, two nurses, and a lay, social services, and health authority representative. Individuals were allocated places on the board by varying processes of election (general practitioners), appointment (lay member), nomination or volunteering (health authority and social services), or a combination of all three (nurses).

\section{Key tasks before 1 April 1999}

Each of the groups had its first official "shadow board" meetings in early November. Each of the boards chose to set aside at least one day as early as possible to clarify, prioritise, and allocate key tasks and also to learn about the personalities, skills, and expertise of 


\section{Key tasks for South and West Bradford} Primary Care Group to April 1999

To be completed:

- Appoint chief officer

- Appoint staff and agree personnel strategy for 1999/2000

- Agree PCG "modus operandum" (constitution and accountability framework)

- Have budgets in place

- Agree information strategy (including information technology)

- Establish appropriate communication systems and channels

- Agree service agreements for secondary care providers for 1999/2000 in collaboration with the health authority

- Complete first stage of primary care investment plan-analysis of current infrastructure

- Agree board lead on quality and clinical governance

- Undertake detailed discussion and agreement of outline medium term objectives

To be discussed and agreed:

- Philosophy, approach, and functions of proceeding at level 2 from 1 April 1999

- Pace of change to achieve level 2 status

- Systems and structures to support PCG next year-including a financial framework and commissioning approaches

- Methodology for health needs assessment

- Approach and mechanisms for involving the public

- Approach to quality and clinical governance and how it will integrate into medium term objectives

- Principles and structures for professional and agency representation through board members

- Philosophy and functions of the management and administration structure

To gain a knowledge and understanding of:

- The infrastructure of the PCG, including primary care and community staff, social services and voluntary sector

- The health improvement programme and health action zone, to ensure appropriate involvement in the creation of the health improvement programme for $1999 / 2000$

Also:

- Identify medium term objectives for 1999/2000

- Produce outline action plans

- Conduct an analysis of the current position of the PCG and its infrastructure

- Conduct a SWOT (strengths, weaknesses, opportunities, threats) analysis of the PCG

other board members. Peter Rennie commented on the value of this: "Until we had the time out day I was kept awake at night worrying about the huge numbers of things we had to address in the time available. At the time out, I felt that a structure was beginning to emerge and it felt more manageable-like having a joint to carve rather than being faced by the whole beast."

Certain statutory objectives must be achieved before April, such as appointing a chair, developing a strategy to address clinical governance, and appointing a chief executive. There are many other challenges (box). Maggie Helliwell argues that there needs to be a huge leap in primary care development to make primary care groups work. This represents "a whole new ball game" and requires "improving skills such as people management, organisational development, clinical governance, and performance management."

To address issues of organisational development, North Bradford Primary Care Group has developed three directorates: commissioning, clinical governance, and primary care development. Lead individuals in each of these areas were identified through skills analysis techniques, group working activities, and a discussion of practical considerations such as availability and interests.

Boards varied in their proposed strategies for user involvement in service development. Common threads are the importance of building on existing contacts with lay and voluntary organisations and of early consultation. Defining health in a broader context than just "health care" by contributing to community development activity and working with a range of agencies, such as local supermarkets (South and West group) and the local authority (City group) was a feature of boards' discussions in their early meetings. All the boards were very keen to utilise the expertise and networks of their lay and social services representatives in their strategies for working together towards improving the health of their local populations.

In the midst of these activities, the health authority is continuing to provide some stability and support. Weekly meetings between the chairs of the primary care group and the health authority provide an opportunity to get to know each other, share ideas, and work towards a consistent approach in activities such as preparing their programmes of action.

As to the future, three of the groups are giving serious consideration to preparing for primary care trust status as soon as legislation permits. John Givans believes it is unlikely that Bradford will have three such trusts, and both the local medical committee and the health authority are keen to promote collegiate working across the groups. He commented, "There are bound to be amalgamations ... and the local medical committee has a significant role to ensure Berlin walls are not erected between primary care groups."

\section{Conclusion}

The commitment to making primary care groups work for the benefit of the people of Bradford was clear from discussions with key players. People are working extremely hard to meet current deadlines, looking to the future, and are generally extremely positive about the potential outcomes of the planned changes. Keith Boughen, project manager of the North Bradford total purchasing pilot, noted that it was important not to consider 1 April 1999 as a watershed. It might be, as far as the whole NHS was concerned; but locally "we feel the primary care group is rolling now. We don't feel that the first of April signals switching on the lights. They are on already."

This paper would not have been possible without the assistance of the following people, to whom we owe grateful thanks: Helen Broadbent, Ann Wagner, John Givans, Lynn Goodwin, Peter Rennie, Keith Boughen, Norman Roper, Laura Hibbs, Barbara Hakin, Tim Callaghan, Maggie Helliwell, and Philip Lewer.

1 Secretary of State for Health. The new NHS. London: Stationery Office, 1997. (Cm 3807.) 